Institutional resistance to veganism : Constructing vegan bodies as deviant in medical encounters in Estonia

\title{
Aavik, Kadri
}

2021-03

Aavik , K 2021 , ' Institutional resistance to veganism : Constructing vegan bodies as deviant in medical encounters in Estonia ' , Health , vol. 25 , no. 2 , pp. 159-176 . https://doi.org/10.1177/136345931986057

http://hdl.handle.net/10138/305155

https://doi.org/10.1177/1363459319860571

acceptedVersion

Downloaded from Helda, University of Helsinki institutional repository.

This is an electronic reprint of the original article.

This reprint may differ from the original in pagination and typographic detail.

Please cite the original version. 
Published in:

Health: An Interdisciplinary Journal for the Social Study of Health, Illness and Medicine, July 3, 2019

https://journals.sagepub.com/doi/full/10.1177/1363459319860571

DOI: $107.171 / 1773 / 61346354953913918986600571$

\title{
Institutional resistance to veganism: Constructing vegan bodies as deviant in medical encounters in Estonia
}

\section{Kadri Aavik}

Tallinn University, Estonia; University of Helsinki, Finland

\begin{abstract}
This article examines institutional resistance to veganism, with a focus on the medical system. Based on a qualitative analysis of vegans' accounts of medical encounters in Estonia, collected via an online questionnaire, I argue that the vegan body is socially constructed as a deviant entity by medical professionals. I suggest that the medical professionals' perceptions of vegans are based less on the actual conditions of their bodies but more on ideas about what are socially and politically acceptable identities and (bodily) practices. Deviance is produced through association with the uneasy category of 'vegan'. The experiences of vegans in the medical system illuminate the role of powerful social institutions in resisting transition towards more ethical and ecologically sustainable food practices and in endorsing human exploitation of other animals.
\end{abstract}

\section{Keywords}

deviance, Estonia, medicine, speciesism, veganism

\section{Introduction}

Veganism, the practice of abstaining from consuming non-human animals primarily for ethical, health and environmental reasons, has become increasingly widespread and visible particularly in Western Europe and North America, as well as in some other parts of the world. ${ }^{1}$

The rise of veganism has largely been driven by individual efforts and civil society action. Institutions, particularly governments, have not supported, but mostly hindered transition towards more ethical human-animal relations and sustainable plant-based diets. This is evidenced by legislation endorsing the use of other animals (e.g. Schaffner, 2011), extensive government subsidies to meat and dairy producers (e.g. Vyas, 2019: 135) and national dietary guidelines of many countries promoting the consumption of animal-based foods. The institutionalised nature of the exploitation of non-human animals is captured by the concept of the animal-industrial complex, referring to the entanglement of various private- and public-sector stakeholders, including governments, on a global scale, to turn other animals into objects of consumption (Noske, 1989; Twine, 2012). In this context, institutional resistance to more ethical and 
sustainable ways of eating is hardly surprising, given that social institutions operate according to speciesist values and principles (Nibert, 2002). Speciesism entails assigning lesser value to and exploiting non-human beings based on the category of species (Ryder, 1970; Singer, 1975).

Many animal and environmental activists, critical animal studies (CAS) and other scholars, and increasingly, some prominent international organisations, have called for the adoption of (largely or only) plant-based diets as more ethical and sustainable ways of eating able to address the current ecological crisis and exploitative human-animal relations. Vegan diets have been found to have a significantly lower environmental impact than animal-based diets (Poore and Nemecek, 2018). Probyn-Rapsey et al. (2016: 136) have called for institutions to support commitments to 'interspecies sustainability' in endorsing more sustainable food practices that entail moving away from animal-based diets. More recently, the EAT-Lancet Commission on Food, Planet, Health has called for radical transformations to our food systems on a global scale - a Great Food Transformation - where our food should be healthy as well as sustainably produced, inextricably linking these two aspects. Such food envisioned by the Commission is largely plant-based (Willett et al., 2019).

I suggest that in popular culture, veganism tends to be regarded primarily as an identity, lifestyle, dietary choice or a consumption practice. These conceptualisations, how- ever, dismiss or downplay political dimensions of veganism specifically and of food practices more generally and ways in which they are enmeshed with various systems of power (Adams, 1993; Jenkins and Twine, 2014). For example, inequalities based on gender, race, class and their intersections play an important role in how we relate to and access food (for more on this, see e.g., Williams-Forson and Wilkerson, 2011). Seeking to politicise food choices and practices, I consider veganism in this article as a transgressive (Twine, 2014) and an embodied political practice which has the potential to disrupt established social order and institutions which rely on human dominance over other animals. Vegans 'contest the everyday commodity status of nonhuman animals' and offer 'ways of doing human/animal relations' differently (Twine, 2017: 167).

With the spread of veganism, institutions are increasingly encountering vegans whose presence has the potential to uncover and disrupt institutional speciesism. In this article, I examine institutional resistance to veganism, focusing on the medical establishment. I provide an empirical exploration of how vegan bodies are constructed in medical encounters. I draw on qualitative empirical data I collected for a study mapping the experiences of vegans in the medical system and with medical professionals in Estonia (Aavik, 2018). My analysis suggests that the vegan body is constructed as a deviant entity in the Estonian medical system. In this article, I demonstrate how this is accomplished, relying on the accounts of vegans. I then discuss how the deviant vegan body is disciplined in medical encounters by practitioners whose power rests in their institutional roles. Finally, I con- sider some implications of these findings for vegans and for transition towards more ethical and sustainable food practices.

I situate this work in the intellectual and activist commitments of CAS, an emerging field of inquiry that explicitly identifies current human-animal relations as exploitative (e.g. 
Taylor and Twine, 2014), and as such, in a profound state of crisis, with implications for the entire planet (Best et al., n.d.). Beyond ethical concerns, there is strong evidence of the unsustainability of animal-based food systems and their detrimental effect to ecosystems and climate (GRAIN and the Institute for Agriculture and Trade Policy, 2018; Kemmerer, 2014; Poore and Nemecek, 2018; Steinfeld et al., 2006).

This article contributes to an emerging set of work on the material and embodied dimensions of veganism with a more explicit engagement with the vegan body. Previous scholarship on this theme has included critical examinations of popular associations of veganism with eating disorders (Wright, 2015), sizeism and fat vegan bodies (Wrenn, 2017), vegan identities and bodies as gendered (Wright, 2015), including work on vegan men and masculinities (Brady and Ventresca, 2014; Greenebaum and Dexter, 2017; Wright, 2015); veganism, race and whiteness (Harper, 2010; Ko and Ko, 2017; Polish, 2016); and vegan sexuality (Potts and Parry, 2010). In addition, some work has discussed ways in which vegans disrupt established social norms, examining the transgressive figure of the 'vegan killjoy' (Grant and MacKenzie-Dale, 2016; Twine, 2014).

I aim to add to this existing work on the vegan body by considering an institutional dimension. I seek to provide insight into institutional resistance to veganism as an embodied and political practice, using the example of the medical system. Until now, most mainstream institutions and prominent international organisations, including medical groups, have been slow to endorse veganism as a feasible solution to the global eco- logical crisis. ${ }^{2}$ This article provides insights into the role of institutions and institutional resistance in the transition towards plant-based diets and non-exploitative human-animal relations.

\section{Deviance as socially constructed and embodied}

A brief discussion of the concept of deviance and how it could be applied to veganism is apt to understand how vegan bodies are constructed in medical encounters. In its most basic meaning, deviance refers to behaviours or ways of being that violate social norms and disrupt established social order. Howard Becker's sociological approach provides a useful understanding of deviance as socially produced and involving power relations between hegemonic and non-hegemonic social groups and practices. In Becker's (1963) conceptualisation, 'social groups create deviance by making the rules whose infraction constitutes deviance, and by applying those rules to particular people and labelling them as outsiders' (p. 9). Thus, 'deviance is not a quality of the act the person commits, but rather a consequence of the application by others of rules and sanctions to an "offender" (Becker, 1963: 9). In other words, deviance is not inherent to some people or practices, but socially constructed, in relation to what is considered 'normal' or nondeviant.

Because vegans violate the norm of bodily sustenance by foods based on non-human animal bodies, they may be constructed as outsiders and deviants. This highlights how bodies are not natural objects, but social and cultural constructs (Adelman and Ruggi, 2015; Featherstone et al., 1991; Shilling, 2003 [1993]), functioning 'as powerful semiotic fields for staging passionate political demands' (Terry and Urla, 1995: 5). Bodies, then, are political entities. 
In this article, I am particularly interested in the embodied dimensions of deviance. Deviance is always in some sense embodied (Terry and Urla, 1995: 2) - in other words, rooted in the body or having a bodily dimension. A number of scholars have highlighted how certain bodies have historically been and continue to be rendered deviant in North America and Europe - for example, women's bodies (Brook, 2004), black and other racialised bodies (Gray, 2012), disabled bodies (Davis, 1995), queer and homosexual bodies (Terry, 1995) and fat bodies (Murray, 2007). Markers of difference are sought in these bodies, particularly in those that are located at the intersection of these categories, such as, for example, black plus-sized women's bodies (BeauboeufLafontant, 2003). Bodies are not rendered deviant because of what is 'inherent' in them, but 'simply because of their subordinate location in systems for distinguishing gender, ethnicity, class, and race' (Terry and Urla, 1995: 5). Similar to how women's bodies are situated in patriarchy and black bodies in white culture, vegans in 'meat culture' (Potts, 2016) stand out as marked. This forms a basis for them being rendered deviant in various institutional contexts.

Foucault (1995) speaks of docile bodies produced by modern systems of discipline, coerced in various subtle and overt ways by which the body becomes 'the site of subjugation' (Pylypa, 1998: 22). This involves people subjugating themselves to power and political order through habitual everyday bodily practices, including food practices. When applied to veganism, it could be argued that in the context of meat culture and speciesist institutions, docile bodies are those that rely on animal products for nourishment. Docile subjects do not contest animal exploitation embedded in our social institutions and normative discourses on human-animal relations. Veganism and vegan bodies have the potential to unsettle this speciesist docility. From this perspective, veganism could be framed as positive deviance (Herington and van de Fliert, 2017) that seeks to challenge the social norm of using other animals for human purposes and the institutionalised violence this entails. In other words, vegans can be thought of as 'positive deviants' who foster positive social change (Herington and van de Fliert, 2017: 3 ), manifested in promoting more ethical human-animal relations as well as pursuing healthier and more sustainable ways of living.

\section{Speciesism, social institutions and deviance}

Following Gramsci's conceptualisation of cultural hegemony, social institutions can be thought of as guardians of normative social order, upholding social norms and serving the interests of hegemonic groups. Feminist social theorists have shown how society and social institutions are gendered (Acker, 1992; Kimmel, 2000; Marshall and Witz, 2004; Winkler, 2010). This means that 'gender is present in the processes, practices, images and ideologies, and distributions of power in the various sectors of social life' (Acker, 1992: 567). Similarly, scholars of LGBTQ+ studies speak of heteronormative institutions, which assume and promote heterosexuality as the 'correct' or desired sexual orientation (Cordeiro-Rodrigues, 2018). Likewise, we can think of speciesism as implicitly but firmly embedded in social institutions (Nibert, 2002) such as medicine. To apply Acker's (1992) insights on how gender is constitutive of social institutions, human domination of animals has 'been built into ordinary institutional functioning' ( $\mathrm{p}$. 568). Institutions such as politics, science, education and medicine uphold the practice of eating other animals through various explicit and more tacit means and support each other in doing so. They work to reinforce the 'cultural hegemony' of animal products 
(Fitzgerald and Taylor, 2014: 165). The institution of medicine (and, its close ally, the pharmaceutical-industrial complex, see Twine, 2013) is an integral part of the animalindustrial complex (Noske, 1989; Twine, 2012), endorsing and participating in animal oppression.

Institutions play a key role in the construction and management of deviance and deviant bodies. In the Foucauldian approach, deviance is produced by institutions through discourses. This involves the categorisation of people into deviant groups, such as the mad, the homosexual and so on upon which they become objects of treatment. According to Foucault (1977), this process serves to reinforce and uphold accepted moral standards that the deviant behaviour is seen to threaten. This classification relies on an (often implicit) understanding of 'normality' (for a discussion of power, norms and normality based on Foucault's work, see Nettleton et al., 2012). Institutional representatives act as 'judges of normality' (Foucault, 1977: 304). The study of deviance in institutional con- texts has also focused on other aspects. For example, Goffman's (1961) work on mental asylums highlights how microinteractions within institutions function to construct deviance.

Thus far, (micro)interactions of vegans with(in) speciesist social institutions, particularly in more embodied forms, has received little scholarly attention. Existing work has focused primarily on derogatory media representations of veganism and vegans (Aavik, 2017b; Cole and Morgan, 2011).

\section{Medicine, bodies, deviance and power}

Medicine and medical encounters are never just about illness and health. Medicine concerns and (re-)organises our ethical, social and political relations (Michael and Rosengarten, 2012: 4). Medicine, similar to other institutional practices and discourses, is not neutral in terms of the knowledge it relies on and disseminates, but stems from particular perspectives and interests (Pylypa, 1998: 23).

Medicine is a site where power and knowledge are inextricably linked (Foucault, 1977), with material effects on bodies. Foucault (1975) highlights how the medical profession's use of scientific knowledge gives it power to define reality, rendering medicine itself as hegemonic knowledge. Thereby, medicine "acquired the power to define the "normal" and identify the 'deviant" (Pylypa, 1998: 23). In addition to constructing deviant bodies, the institution of medicine has the power to discipline them by legitimising certain identities and bodily practices while rendering others deviant. Institutional disciplining of the body (Pylypa, 1998: 22) functions to 'optimize its capacities, extort its forces, increase its usefulness and docility, integrate it into systems of efficient and economic controls' (Foucault, 1980: 139), producing 'the types of bodies that society requires' (Pylypa, 1998: 22). In speciesist societies, institutions endorse bodies that rely on animals for nourishment. Speciesism is embedded in the institution of medicine and the knowledge it relies on and produces. In large part, medical knowledge relies on the use of non-human animals, evidenced by the ubiquitous use of animals in medical experiments (Birke, 2012).

Medical encounters are powerful sites where bodies are assigned meaning and where established social norms are upheld (or contested), as they 'convey ideological 
messages supportive of the current social order' (Waitzkin, 1989: 220). For example, the medical discourse implicitly delivers messages about work and our role as workers as well as about the family and gender relations in society, thereby implicitly approving and reinforcing certain hegemonic ways of social organisation, while muting dissenting voices and rendering certain bodies as deviant (Waitzkin, 1989). Similarly, veganism constitutes an ideological element in the context of medical encounters. In these encounters, bodies are rendered 'normal' or 'pathological', depending on a range of bodily markers (Murray, 2007: 361). I suggest that veganism - while not a visible bodily marker - constitutes one such key marker by which certain bodies are distinguished as non-normative.

\section{Veganism and its institutional reception in Estonia}

Veganism is a new social and cultural phenomenon in Estonia, having gradually emerged alongside and intertwined with the rise of the animal advocacy movement roughly from the second half of the 2000s (Aavik, 2019). While veganism is gaining cultural visibility and is increasingly practised, particularly by young, educated, urban ethnic Estonian youth, ${ }^{3}$ its institutional reception has been less successful.

Mainstream media coverage of veganism has focused primarily on human health and has been largely negative, particularly when it comes to children's health. I have argued elsewhere that the latter issue has at times taken on the proportions of a moral panic (Aavik, 2017b). Concern over potential detrimental effects of veganism on children's health, expressed by journalists and some medical professionals, has taken precedence over other depictions of veganism. Animals and their well-being have largely remained absent from these discussions, similar to the findings of Cole and Morgan (2011) of the media coverage of veganism in the United Kingdom. This attests to the deeply speciesist foundations of this coverage as well as of the institution of media more broadly.

Of particular relevance to this article is the reception of veganism by the medical and nutrition establishment. The Estonian national dietary guidelines (Pitsi et al., 2017), compiled by leading nutrition experts in the country, deem eating animal- based foods essential and declare veganism as unsuitable for human health (Aavik, 2017a). ${ }^{4}$ As a recent development, the Estonian Health Board officially recognised vegan menus in kindergartens, as a result of lengthy lobbying process by the Estonian Vegan Society. ${ }^{5}$

\section{Research design, materials and methods}

I draw on qualitative data that I collected in 2017 via an online questionnaire for the Estonian Vegan Society. This data collection sought to map experiences of vegans with medical institutions and professionals in Estonia (Aavik, 2018). It was undertaken with the aim to understand how vegans navigate the Estonian medical system and the kinds of support they are seeking from medical professionals, given the predominantly hostile and unsupportive signals originating from the medical and nutrition establishment, as outlined earlier.

Data were collected through Google Forms from September to November 2017. The questionnaire consisted of open questions, with no restrictions to the length of answers. Research participants were encouraged to describe their experiences in detail and to 
bring examples of particular encounters. As the central question, participants were asked to describe their medical encounters in Estonia as vegans (including experiences with general practitioners (GPs), specialised doctors and hospitals). They were invited to share their expectations towards the Estonian medical system and medical professionals in terms of the support they were seeking as vegans. No personal data were gathered and the data were collected anonymously; however, those who wished could leave their con- tact information so that the author of the study could contact them for further information. Roughly, half of the participants did so. All research participants remain anonymous in this article.

Information about the study and a link to the questionnaire were distributed via the Estonian Vegan Society webpage and Facebook page as well as in other Estonian language vegan-themed Facebook groups. All vegans having experience with the medical system in Estonia were encouraged to take part.

Altogether, 110 people participated. Their average age was 29.7 years. Most research participants (78) lived in major Estonian cities, with a smaller number inhabiting small towns (19) and rural areas (7). Out of the 110 participants, 101 identified as women. This reflects the gender composition of the Estonian vegan community where approximately 75-80 per cent identify as women, ${ }^{6}$ men's more infrequent visits to medical professionals (Eurostat, 2014), and men's generally lower participation rates in online surveys compared to women (Smith, 2008), to name a few factors shaping this outcome.

According to the standards of research ethics in the Estonian research community, this type of research does not require obtaining permission from an ethics committee. Before filling out the questionnaire, research participants were given information about the study and its aims. They were ensured that they remain anonymous in all publications based on the collected data (this applies to those who provided their contact details, as others cannot be identified from their responses). By proceeding to the questions, research participants indicated their informed consent.

I conducted qualitative thematic analysis of the material (Braun and Clarke, 2006), beginning with a more inductive approach and, at a later stage, transitioning to more theoretically driven analysis. My initial inductive analysis revealed reports of derogatory attitudes towards veganism and vegan patients by medical professionals. Guided by these initial findings, I conducted a more detailed, theory-driven examination to better understand this phenomenon. Employing the concept of deviance, I sought to understand how vegan bodies are constructed in medical encounters. Saturation was reached when I did not find any new instances in the data that related to the notion of deviance as the central concept driving the analysis. In the presentation of findings, I use extracts from the responses to illustrate these themes. I have translated these excerpts from Estonian into English.

The study is not representative of the Estonian population and does not provide causal explanations, but seeks to obtain specific insight into the construction of vegan bodies in medical encounters. The concept of deviance is also helpful to understand experiences framed as positive, as I show in the subsequent analysis. 


\section{Analysis and findings: constructing and disciplining the deviant vegan body}

Vegans reported both positive and negative experiences (the latter prevailed) with medical professionals. I do not aim here to present 'both sides', but to focus specifically on how the vegan body was constructed as deviant, as represented in the accounts of the research participants. The following analysis is divided into two themes which exemplify specific ways in which this was accomplished. The analysis ends with a discussion of how the deviant vegan body is disciplined in the medical system.

\section{The malnourished vegan body}

A key way in which medical professionals produced the deviant vegan body was to regard it as inherently flawed. This typically occurred upon learning about the patient's vegan- ism, regardless of what was known about the health status of the patient's body. More specifically, the vegan body was perceived as necessarily malnourished, due to the lack of animal products in the diet that allegedly provide the body with adequate sustenance:

I once mentioned [to my doctor] that I don't eat meat and don't drink milk. I then learned that this is a folly that I shouldn't go along with. If meat and milk provide easy nourishment for the body, then why am I starving myself?

In this instance, veganism is viewed by the medical professional as a trend, which inevitably involves and even constitutes starvation and malnourishment of the body. Moreover, veganism is seen as unnecessary. As a fad, it could and should be easily abandoned, in favour of a 'properly nourishing' animal-based diet. Those who go vegan are seen as taking unwarranted risks that pose a threat to their bodies and make their lives needlessly complicated by giving up animal products, as allegedly the best sources of nourishment.

Malnourishment was, for example, assumed to manifest in vitamin deficiencies. The judgement that a vegan body necessarily lacks vitamins was made before knowing anything specific about the particular patient's health condition:

The last time when I asked my GP to check my blood, I mentioned that I'm vegan when calling in to book an appointment. The doctor announced immediately that in that case I am deficient in iron, calcium and vitamins B and D.

This reported experience reflects disbelief on the part of medical professionals in the possibility of a healthy and adequately nourished vegan body. Furthermore, even in cases where medical tests were performed and came back normal, medical professionals may find it hard to believe that a vegan patient could be healthy:

My [blood] results were reported to me by the nurse who was very surprised at such perfect results.

Even further, vegan bodies that were deemed healthy at present were constructed as being in the state of imminent failure and at permanent risk of malnourishment: 
When looking at my blood tests, the doctor told me that everything is perfect, but sooner or later

I will develop severe iron deficiency and I will have to start eating meat.

One particular way in which veganism was linked to malnourishment, was its conceptualisation as an eating disorder:

Upon learning about my veganism, my GP wanted to send me to a psychiatrist, as s/he ${ }^{7}$ considered my veganism an eating disorder.

Labelling veganism as an eating disorder speaks of the medical professionals' attempt to fit veganism into an existing medical classification of pathologies. According to standard medical definitions, an eating disorder is a mental condition, which has a negative effect on the patient's physical and mental health (American Psychiatric Association, 2013). Thus, it is seen as pathological, a departure from 'normal' ways of eating, and hence subject to treatment. As defined in the medical discourse, eating disorders typically involve obsession over body weight (such as in the case of most commonly known eating disorders of anorexia, bulimia and binge eating). As such, an eating disorder is not motivated by ethical considerations. Categorising veganism as an eating disorder suggests the Estonian medical professionals' understanding of veganism as a diet motivated by unhealthy obsession with weight or body image. This labelling completely dismisses the political dimension of veganism, and a typical reason behind veganism: concern over the lives of non-human animals. Hence, constructing veganism and vegan bodies as such constitutes a speciesist move where the only entity that matters is the human.

\section{Veganism as a source of all health problems}

The construction of veganism and vegan bodies as deviant is exemplified in accounts where research participants present experiences with medical professionals who associated all their medical problems with veganism:

My GP always scolds me for not eating eat. From time to time I request blood tests to learn about my health, but to get the blood tests, I have to have a medical concern. But if I complain about something, for example that I am tired or something like that, the doctor tells me that this is because I do not eat meat, but only cabbage and carrot.

Tiredness is a symptom that can have a number of causes, but here, veganism is seen an easy culprit: there is no need to look further for a cause of the said medical problem. Instead, the medical professional seems to rely on a common myth regarding the health of vegans, according to which a vegan diet does not provide enough protein, which causes tiredness. This framing also suggests the medical professional's understanding of veganism as an extreme and unnecessary self-imposed dietary restriction. As such, veganism is bound to lead to serious health problems and an unhealthy body.

In some cases, research participants reported experiences where their health issues, such as dental problems or traumas, were seen as caused by veganism:

My dentist knows that I am vegan, but s/he does not approve of my lifestyle. According to him/ her, all my cavities are related to veganism. This is despite the fact that I have had cavities since my early teens when I was an omnivore, with a healthier than average diet. 
What is notable here is the association of veganism with health problems that are not linked to veganism in a plausible way, without evidence.

The fear of medical processionals' prejudice and particularly their potential association of various health problems with veganism was the main reason why many respondents did not mention their veganism to medical professionals or avoided visiting doctors altogether:

I have not visited my GP for over ten years. First, I haven't had the need to and second, I do not wish to hear the doctor's negative attitudes. Once a year, I do blood tests on my own cost, to check that everything is okay. A couple of times over these years I have also gone to a private specialist, to avoid visiting my GP. I do not mention my veganism to doctors because I don't want them to develop prejudice towards me and I don't want them to form their judgements about my health purely based on how I eat. I know of cases where vegans have been denied medical help and the correct diagnosis because the doctors implicitly assume that the problems are surely related to veganism.

These experiences speak of lack of trust of vegans towards medical professionals due to biases that many doctors hold or are assumed to hold towards veganism. The resulting action of vegans taking matters in their own hands regarding their healthcare or worse, avoiding medical encounters altogether, may yield adverse effects to the health of vegans.

Disciplining the deviant vegan body: calls for meat consumption and heightened surveillance

In this section, I take a closer look at the ways that the deviant vegan body was disciplined in medical encounters. I identified two main means by which this was accomplished.

Calls for meat consumption. The first involved calls by medical professionals to 'correct' the deviance of veganism by encouraging vegans to eat animal products:

I have not visited the doctor much while I've been vegan, because my health has been good. But not long after I adopted a plant-based diet, I got iron deficiency (I think from stress). The doctor was adamant that I have to start eating liver and stop this nonsense.

This account demonstrates the disregard of the medical professional towards the patient's identity and politics, by suggesting that a vegan patient eat meat to overcome a health problem. It becomes evident how the doctors operate in a speciesist framework, where animal products are seen as the only way for a body to become healthy. This position suggests that vegan bodies can never be healthy.

The calls for eating animal products were also made in the context of children's veganism, which appeared as a source of heightened concern for medical professionals in the accounts provided by the research participants:

When I said to my GP that I am vegan, s/he immediately assumed that I was deficient in iron, which I wasn't. I had just given a lot of blood samples when pregnant, everything was okay. When my child was a baby, we had to make frequent visits to the GP. My child is vegan from birth. When s/he started eating solid food, the GP insisted that I give him/her meat, to avoid iron deficiency. [...] My child's iron levels were okay. 
Another reported recommendation by a medical professional reflects a desperate attempt to rely on animal products for the sustenance of healthy bodies:

The nurse recommended that I secretly hide meat in my child's food or at least boil vegetables in meat broth.

These accounts speak of the glorification of animal products by some medical professionals. As these examples suggest, animal-based foods are elevated to the status of almost magic ingredients capable of providing substantial health benefits. Without these, bodies, particularly of children, are seen as incapable of functioning properly.

Heightened surveillance of vegan patients. The second way in which vegans were disciplined involved placing vegan bodies under heightened medical surveillance. In contrast to 'normal' bodies consuming animal products and therefore 'safe' to be left at their own devices, vegan bodies - constructed as 'at risk' - were seen as in need of heightened medical attention. The perception of the vegan body as in need of surveillance by the medical system was apparent even in experiences framed mostly or entirely positive by the research participants:

I visited my GP every three years for a medical certificate. When I said that I'm vegan, the doctor's attitude was fine. S/he suggested him/herself to do some bloodwork, which I did. The results were good.

Such experiences attest that the medical professionals operate from the presumption that the vegan body - even if outwardly healthy and without any complaints by the patient - must inevitably be in some way lacking nutrients. This doubt in the possibility of a healthy vegan body (in the long term) manifests itself in the recommendation of regular check-ups:

My experience with my gynaecologist was very positive. I notified him/her from the beginning about my diet. S/he was very understanding and said that as long as I do it right, it won't damage me. Just in case (to see if I eat properly), s/he sent me to do various medical tests. It turned out that everything was fine.

The latter excerpt shows the medical professional's concern and mistrust over a vegan patient's eating habits. Behind this concern is also the assumption that veganism, as opposed to animal-based eating, can easily be 'done wrong', with dire bodily consequences.

\section{Discussion and conclusion}

In this article, I have argued, using the concept of deviance, that the vegan body is marked and constructed as deviant in medical encounters, drawing on the experiences of vegans based in Estonia. Such construction of vegan bodies was accomplished through deeming them as necessarily malnourished, unhealthy or in a state of imminent failure. In this understanding, vegans are not and cannot be healthy. Instead, their bodies were rendered as inherently at the risk of malfunctioning. As deviant, vegan bodies became the subject of disciplining. This involved advice from medical professionals encouraging vegans to resume eating animals and placing their bodies under heightened medical surveillance. 
As "deviant bodies" have been used to implicitly and intricately shore up notions of what is normal and what is not' (Terry and Urla, 1995: 5), these findings also contribute to understanding the entity that is the 'normal' unmarked body. For Estonian medical professionals, a 'normal' or 'non-deviant' body draws sustenance from consuming other animals and their bodily fluids.

On the one hand, the findings suggest that Estonian medical professionals view veganism as a lifestyle project and an act of personal risk-taking, as evident from suggestions to abandon veganism. As such, it should not receive institutional support by the medical establishment, but is to be discouraged. This framing relates to the depiction of veganism as a 'self-restricted' diet in the Estonian dietary guidelines (Aavik, 2017a), suggesting that veganism is a self-imposed, unnecessary and reckless bodily restriction - it 'is dissociated from its connection with debates concerning nonhuman animals' rights or liberation' (Cole and Morgan, 2011: 134).

Yet, on the other hand, there is reason to suggest that this engagement with veganism and vegans is not simply over a kind of diet, but is in fact implicitly political, with a strong ideological component. Within a speciesist framework, vegans are seen as a threat to established social order relying on the consumption of other animals. This is evidenced by the fact that the medical establishment and medical discourse (including national dietary guidelines) in Estonia have not produced similar moral panics around other diets or issues such as increasing child obesity. The institutional policing of those who abstain from consuming other animals and advocate for the end of this practice is evident in government repression of animal liberation activists who have received harsher treatment than advocates for many other social justice causes for similar kinds of political activism (Gazzola, 2015; Griffin, 2017; Potter, 2011).

These insights suggest that the perception and treatment of vegans by representatives of the medical system is shaped by vegans challenging the normative ideal of the body as one sustained by animal products, requiring the continued systematic use of other animals for human purposes. Deviance here is then produced on the basis of what is socially and politically acceptable and what is not. It is belonging to the uneasy category of 'vegan' that produces deviance in the medical encounters. As Becker (1963) highlights, deviance is not something inherent in those labelled as such, but rather produced by casting people or groups as outsiders based on them violating accepted social norms. It is in a context where consuming animal products is a norm that veganism becomes seen as a form of bodily transgression. This helps to explain how medically healthy vegan bodies were rendered pathological and deviant in the medical encounters and constructed as permanently at the risk of malnourishment. Hence, the medical professionals' perception of vegans is not based on the actual condition of their bodies, but on what they represent.

The medical professionals' constructions of the vegan body stem from and reflect attitudes towards veganism and veganism in the broader society and in other social institutions. Also, more specifically, this institutional disapproval originates from the lack of contemporary evidence-based knowledge regarding nutrition, let alone vegan nutrition, in medical training in Estonia. ${ }^{8}$ 
The ways in which medical professionals construct vegans and vegan bodies have important implications for human-animal relations and sustainability efforts, including for interspecies sustainability (Probyn-Rapsey et al., 2016: 136). For individual vegans, having their veganism challenged by medical professionals could be thought of as a form of institutional betrayal (Smith and Freyd, 2014). Institutional betrayal refers to 'trusted and powerful institutions [...] acting in ways that visit harm upon those dependent on them for safety and wellbeing' (Smith and Freyd, 2014: 575). Being rendered deviant and disciplined as vegans by medical professionals may lead to vegans not disclosing their veganism to medical professionals or avoiding medical encounters altogether, as also suggested by findings of this study. This may result in potential health problems remaining undiagnosed (in time). In addition, I suggest that negative attitudes of health professionals towards vegans, in combination with the prevalent nutritional knowledge in Estonia denouncing veganism as a viable diet, may lead vegans to construct their own bodies as deviant. This has the effect of producing selfdisciplining practices, exemplified by healthy vegans requesting blood tests, as a precautionary measure, as they assume that the vegan diet may leave their bodies lacking essential nutrients.

At the same time, there are broader implications beyond immediate consequences to vegans. The accounts of medical encounters studied here illuminate how the medical system, by constructing vegans as deviant, hinders the rise of veganism as a more ethical and ecologically sustainable food practice compared to conventional meat-based diets. Thus, beyond understanding the experiences of vegans in medical encounters, this article has illuminated how institutions are implicated in reproducing a speciesist social order (Nibert, 2002) by rendering deviant those who challenge it. Furthermore, from the point of view of public health, veganism could 'provide health benefits for the prevention and treatment of certain diseases' (Melina et al., 2016). Speciesist institutions that construct veganism as deviant prevent considering the vegan diet as an obvious and accessible way to improve public health outcomes.

\section{Declaration of conflicting interests}

The author(s) declared no potential conflicts of interest with respect to the research, authorship and/or publication of this article.

\section{Funding}

The author(s) disclosed receipt of the following financial support for the research, authorship and/or publication of this article: My research for this article was conducted in the framework of the project 'Climate Sustainability in the Kitchen: Possibilities for Transforming Everyday Food Culture' at the University of Helsinki and funded by the Kone Foundation in Finland.

\section{Notes}

1. According to The Vegan Society (2018), vegans make up at least 1.16 per cent of the population in the United Kingdom, making veganism 'the fastest growing lifestyle movement' (n.p.). In 2014, 1 per cent of the US population reported to be vegan, with a considerable increase to 6 per cent in 2017 (GlobalData, 2017). 
There has been a nearly sixfold rise in Google searches of the term 'veganism' over the past 10 years (Google Trends, 2019), with most searches originating from Australia, Israel, New Zealand and Canada.

2. In the area of medicine, a notable exception is the Physicians Committee for Responsible Medicine (2018) which promotes a plant-based diet as optimal for human health.

3. In 2018, the proportion of vegans in the Estonian population was 0.6 per cent. The percentage is highest among 15-24-year olds: 3.2 per cent (TNS EMOR, 2018)

4. While veganism is not endorsed in national dietary guidelines of most Western countries, it is at least accepted as suitable and nutritionally adequate for people in all stages of life (Melina et al., 2016; Nordic Council of Ministers, 2012).

5. This decision does not mean that kindergartens are obliged to serve vegan food, but that at the request of parents and at the willingness of kindergartens, vegan food is allowed to be served.

6. This percentage is an estimation based on the membership of the largest veganthemed Estonian language Facebook group Eesti veganid [Estonian Vegans], as no reliable statistical data are available on the gender composition of the Estonian vegan community.

7. The Estonian language does not have grammatical gender. The same pronoun is used to refer to people of all genders. Therefore, it is impossible to distinguish the gender of the medical professionals mentioned. Hence, I use 's/he' to refer to them.

8. The curriculum of medicine at Tartu University, the only medical school in Estonia, where the vast majority of Estonian doctors have graduated from, does not include courses on nutrition. See https://www.is.ut.ee/rwservlet?ok_oppekava_kirjeldus.rdf $+533+2019+1+0+2+$ $0,0,0,0,0,0,0+\mathrm{PDF}+$ application/pdf for the curriculum of the academic year $2019 / 2020$.

\section{ORCID iD}

Kadri Aavik https://orcid.org/0000-0001-7028-5927 


\section{References}

Aavik K (2017a) Nonhuman animals as 'high-quality protein': Insistence on the consumption of 'meat' and 'dairy' in the Estonian nutrition recommendations. In: Nibert D (ed.) Animal Oppression and Capitalism: Oppression of Nonhuman Animals as Sources of Food, vol. 1. Santa Barbara, CA; Denver, C0: Praeger Press, pp. 140-165.

Aavik K (2017b) 'Stop forcing veganism on Children': Not eating non-human animals as a source of moral panic in Estonia. In: Nonhuman animals in society: Exploring new pathways for resistance, change and accommodation: The 5th European conference for critical animal studies, Lund, 26-28 October 2017.

Aavik K (2018) Veganite kogemused Eesti meditsiinisüsteemis: uuringuraport [The experiences of vegans in Estonian medical system: research report]. Tallinn: Eesti Vegan Selts [Estonian Vegan Society].

Aavik K (2019) The rise of veganism in post-socialist Europe: Making sense of emergent vegan practices and identities in Estonia. In: Wright L (ed.) Through a Vegan Studies Lens: Textual Ethics and Lived Activism. Reno, NV: University of Nevada Press, pp. 151170.

Acker J (1992) From sex roles to gendered institutions. Contemporary Sociology 21(5): 565-569. Adams C (1993) The feminist traffic in animals. In: Gaard G (ed.) Ecofeminism: Women, Animals, Nature. Philadelphia, PA: Temple University Press, pp. 195-218.

Adelman M and Ruggi L (2015) The sociology of the body. Current Sociology 64: 907930. American Psychiatric Association (2013) Diagnostic and Statistical Manual of Mental Disorders (5th ed.). Arlington, TX: American Psychiatric Association.

Beauboeuf-Lafontant T (2003) Strong and large black women? Exploring relationships between deviant womanhood and weight. Gender \& Society 17(1): 111-121.

Becker H (1963) Outsiders: Studies in the Sociology of Deviance. New York: The Free Press. Best S, Nocella AII, Kahn R, et al. (n.d.) Introducing Critical Animal Studies. Institute for Critical Animal Studies. Available at: http://www.criticalanimalstudies.org/wp-content/uploads/2009/09/IntroducingCritical-Animal-Studies-2007.pdf

Birke L (2012) Animal bodies in the production of scientific knowledge: Modelling medicine. Body \& Society 18(3-4): 156-178.

Brady J and Ventresca M (2014) 'Officially a vegan now': On meat and renaissance masculinity in pro football. Food and Foodways 22(4): 300-321.

Braun V and Clarke V (2006) Using thematic analysis in psychology. Qualitative Research in Psychology 3(2): 77-101.

Brook B (2004) Feminist Perspectives on the Body. London; New York: Routledge. Cole M and Morgan K (2011) Vegaphobia: Derogatory discourses of veganism and the 
reproduction of speciesism in UK national newspapers. The British Journal of Sociology 62(1): 134-153.

Cordeiro-Rodrigues L (2018) Nonhuman animal metaphors and the reinforcement of homophobia and heterosexism. In: Nibert D (ed.) Capitalism and Animal Oppression: The Oppressive and Destructive Role of Capitalism, vol. 2. Santa Barbara, CA: Praeger Press, pp. 231-250.

Davis L (1995) Enforcing Normalcy: Disability, Deafness, and the Body. New York: Verso Books. Eurostat (2014) Self-reported consultations - proportion of people having consulted a generalist medical practitioner during the four weeks prior to the survey, by Sex, 2014 (\%). Available at: https://ec.europa. eu/eurostat/statisticsexplained/index.php?title=File:Self-reported_consultations_\%E2\%80\%94_ proportion_of_people_having_consulted_a_generalist_medical_practitioner_during_the_f our_weeks_prior_to_the_survey,_by_age,_2014_(\%25)_HLTH17.png\&

Featherstone M, Hepworth M and Turner B (1991) The Body: Social Process and Cultural Theory. Thousand Oaks, CA: SAGE.

Fitzgerald AJ and Taylor N (2014) The cultural hegemony of meat and the animal industrial com- plex. In: Taylor N and Twine R (eds) The Rise of Critical Animal Studies: From the Margins to the Centre. New York: Routledge, pp. 165-182.

Foucault M (1975) The Birth of the Clinic: An Archaeology of Medical Perception (trans. AM Sheridan Smith). New York: Vintage Books.

Foucault M (1977) Discipline and Punish: The Birth of the Prison. London: Penguin Books.

Foucault M (1980) The History of Sexuality. Volume I: An Introduction (trans. R Hurley). New York: Vintage Books.

Foucault M (1995) Docile Bodies: Discipline and Punish. New York: Vintage Books. Gazzola L (2015) Bad things happened: Metaphorical fingerprints, constellations of evidence, and guilt for association. Vermont Law Review 40: 813-920.

GlobalData (2017) Top trends in prepared foods 2017: Exploring trends in meat, fish and seafood; pasta, noodles and rice; prepared meals; savory deli food; soup; and meat substitutes. Report. Available at: https://www.globaldata.com/store/report/cs1713cttop-trends-in-prepared-foods-2017-exploring-trends-in-meat-fish-and-seafood-pastanoodles-and-rice-prepared- meals-savory-deli-food-soup-and-meat-substitutes/

Goffman E (1961) Asylum: Essays on the Social Situation of Mental Patients and Other Inmates. Garden City, NY: Anchor Books.

Google Trends (2019) Veganism. Available at: https://trends.google.com/trends/explore?date $=2009-04-15 \% 202019-05$ $15 \& \mathrm{q}=\% 2 \mathrm{Fm} \% 2 \mathrm{~F} 07 \_$hy 
GRAIN and the Institute for Agriculture and Trade Policy (2018) Emissions impossible: How big meat and dairy are heating up the planet. Report. Available at: https://www.grain.org/article/ entries/5976-emissions-impossible-how-big-meatand-dairy-are-heating-up-the-planet

Grant J and MacKenzie-Dale B (2016) Lisa Simpson and Darlene Conner: Television's favorite killjoys. In: Castricano J and Simonsen R (eds) Critical Perspectives on Veganism. Basingstoke: Palgrave Macmillan, pp. 307-329.

Gray K (2012) Deviant bodies, stigmatized identities, and racist acts: Examining the experiences of African-American gamers in Xbox Live. New Review of Hypermedia and Multimedia 18(4): 261-276.

Greenebaum J and Dexter B (2017) Vegan men and hybrid masculinity. Journal of Gender Studies 27(6): 637-648.

Griffin NS (2017) Criminalising veganism. In: Griffin N (ed.) Understanding Veganism: Biography and Identity. Basingstoke: Palgrave Macmillan, pp. 99-116.

Harper B (2010) Race as a 'feeble matter' in veganism: Interrogating whiteness, geopolitical privi- lege, and consumption philosophy of 'cruelty-free' products. Journal for Critical Animal Studies 8(3): 5-27.

Herington $\mathrm{M}$ and van de Fliert E (2017) Positive deviance in theory and practice: A conceptual review. Deviant Behavior 39(5): 664-678.

Jenkins S and Twine R (2014) On the limits of food autonomy: Rethinking choice and privacy. In: Taylor N and Twine R (eds) The Rise of Critical Animal Studies: From the Margins to the Centre. London: Routledge, pp. 225-240.

Kemmerer L (2014) Eating Earth: Environmental Ethics and Dietary Choice. Oxford: Oxford University Press.

Kimmel M (2000) The Gendered Society. New York: Oxford University Press. Ko A and Ko S (2017) Aphro-Ism: Essays on Pop Culture, Feminism, and Black Veganism from Two Sisters. New York: Lantern Books.

Marshall B and Witz A (2004) Engendering the Social: Feminist Encounters with Sociological Theory. Buckingham: Open University Press.

Melina V, Craig W and Levin S (2016) Position of the academy of nutrition and dietetics: Vegetarian diets. Journal of the Academy of Nutrition and Dietetics 116: 1970-1980.

Michael M and Rosengarten M (2012) Medicine: Experimentation, politics, emergent bodies. Body \& Society 18(3-4): 1-17.

Murray S (2007) Corporeal knowledges and deviant bodies: Perceiving the fat body. Social Semiotics 17(3): 361-373. 
Nettleton S, Neale J and Pickering L (2012) 'I just want to be normal': An analysis of discourses of normality among recovering heroin users. Health 17(2): 174-190.

Nibert D (2002) Animal Rights/human Rights: Entanglements of Oppression and Liberation. Lanham, MD: Rowman \& Littlefield.

Nordic Council of Ministers (2012) Nordic Nutrition Recommendations 2012. 5th ed. Copenhagen: Nordic Council of Ministers.

Noske B (1989) Humans and Other Animals: Beyond the Boundaries of Anthropology. London: Pluto Press.

Physicians Committee for Responsible Medicine (2018) Vegan diets lead to better health. Available at: https://www.pcrm.org/news/health-nutrition/vegan-diets-leadbetter-health

Pitsi T, Zilmer M, Vaask S, et al. (2017) Eesti toitumis- ja liikumissoovitused 2015 [Estonian nutri- tion and physical activity recommendations 2015]. Tallinn: Tervise Arengu Instituut.

Polish J (2016) Decolonizing veganism: On resisting vegan whiteness and racism. In: Castricano J and Simonsen R (eds) Critical Perspectives on Veganism. Basingstoke: Palgrave Macmillan, pp. 373-392.

Poore J and Nemecek T (2018) Reducing food's environmental impacts through producers and consumers. Science 360(6392): 987-992.

Potter W (2011) Green Is the New Red: An Insiders Account of a Social Movement Under Siege. San Francisco, CA: City Lights Books.

Potts A and Parry J (2010) Vegan sexuality: Challenging heteronormative masculinity through meat-free sex. Feminism \& Psychology 20(1): 53-72.

Potts A (ed.) (2016) Meat Culture. Leiden; Boston, MA: Brill.

Probyn-Rapsey F, Donaldson S, Loannides G, et al. (2016) A sustainable campus: The Sydney declaration on interspecies sustainability. Animal Studies Journal 5(1): 110-151.

Pylypa J (1998) Power and bodily practice: Applying the work of Foucault to an anthropology of the body. Arizona Anthropologist 13: 21-36.

Ryder RD (1970) Speciesism. Oxford: Leaflet.

Schaffner JE (2011) An Introduction to Animals and the Law. Basingstoke; New York: Palgrave Macmillan.

Shilling C (2003 [1993]) The Body and Social Theory. Thousand Oaks, CA: SAGE.

Singer P (1975) Animal Liberation: A New Ethic for Our Treatment of Animals. New York: Avon. 
Smith C and Freyd J (2014) Institutional betrayal. American Psychologist 69(6): 575587.

Smith G (2008) Does gender influence online survey participation? A record-linkage analysis of university faculty online survey response behavior. Research paper, San Jose State University, San Jose, CA.

Steinfeld H, Gerber P, Wassenaar TD, et al. (2006) Livestock's long shadow: Environmental issues and options. Report, Food and Agriculture Organization, Rome.

Taylor N and Twine R (2014) Introduction: Locating the 'critical' in critical animal studies. In: Taylor N and Twine R (eds) The Rise of Critical Animal Studies: From the Margins to the Centre. New York: Routledge, pp. 1-15.

Terry J (1995) Anxious slippages between 'us' and 'them': A brief history of the scientific search for homosexual bodies. In: Terry J and Urla J (eds) Deviant Bodies: Critical Perspectives on Difference in Science and Popular Culture. Bloomington, IN: Indiana University Press.

Terry J and Urla J (eds) (1995) Deviant Bodies: Critical Perspectives on Difference in Science and Popular Culture. Bloomington, IN: Indiana University Press.

The Vegan Society (2018) Veganism in the UK. 10 February. Available at: https://www.vegansociety.com/news/media/statistics

TNS EMOR (2018) The Proportion of Vegans in the Estonian Population (Population Survey). Tallinn: TNS EMOR.

Twine R (2012) Revealing the 'animal-industrial complex': A concept and method for critical animal studies? Journal for Critical Animal Studies 10(1): 12-39.

Twine R (2013) Animals on drugs: Understanding the role of pharmaceutical companies in the animal-industrial complex. Bioethical Inquiry 10(4): 505-514.

Twine R (2014) Vegan killjoys at the table - Contesting happiness and negotiating relationships with food practices. Societies 4(4): 623-639.

Twine R (2017) Materially constituting a sustainable food transition: The case of vegan eating practice. Sociology 52(1): 166-181.

Vyas S (2019) Disease prevention with a plant-based lifestyle. In: Herrmann L and Jayne K (eds) Animal Experimentation: Working Towards a Paradigm Change. Leiden; Boston, MA: Brill, pp. 124-148.

Waitzkin H (1989) A critical theory of medical discourse: Ideology, social control, and the pro- cessing of social context in medical encounters. Journal of Health and Social Behavior 30: 220-239. 
Willett W, Rockström J, Loken B, et al. (2019) Food in the anthropocene: The EATLancet Commission on healthy diets from sustainable food systems. The Lancet 393(10170): 447- 492.

Winkler C (2010) Feminist sociological theory. In: Crothers C (ed.) Historical Developments and Theoretical Approaches in Sociology, vol. 2. Oxford: EOLSS, pp. 47-69.

Wrenn CL (2017) Fat vegan politics: A survey of fat vegan activists' online experiences with social movement sizeism. Fat Studies 6(1): 90-102.

Wright L (2015) The Vegan Studies Project: Food, Animals, and Gender in the Age of Terror. Athens, GA: University of Georgia Press.

Williams-Forson P and Wilkerson A (2011) Intersectionality and food studies. Food, Culture \& Society 14(1): 7-28.

\section{Author biography}

Kadri Aavik is an associate professor of Gender Studies at Tallinn University, Estonia, and a postdoctoral researcher at the University of Helsinki, Finland. She works in gender studies, critical animal studies and vegan studies - and their intersections. Her research interests include vegan identities and practices and the engagement of institutions with veganism and vegans. 